\title{
Studies on Murine Leprosy Bacillus
}

\section{Growth in Relation to Concentrations of Monopotassium Phosphate, Sodium Glutamate and Glycerol in the 1\% Egg Yolk Medium, and in Relation to $\mathrm{pH}$ of the Medium}

\author{
TATsujI OGAWA and MiNAKo HIRAKI \\ (Kitajuku Municipal Hospital at Urawa and Kitasato Institute)
}

The $1 \%$ egg yolk medium ${ }^{1)}$ is prepared as follows: The salt solution consists of $\mathrm{KH}_{2} \mathrm{PO}_{4}, 1.0 \mathrm{~g}$; sodium glutamate, $1.0 \mathrm{~g}$; distilled water, $100 \mathrm{ml}$. Added $6 \mathrm{ml}$ glycerol, $6 \mathrm{ml}$ of a 2 per cent malachite green solution and $200 \mathrm{ml}$ egg yolk to the salt solution, mixed well, and distributed in sterile test tubes (170 mm long, $18 \mathrm{~mm}$ in diameter) in $5 \mathrm{ml}$ amounts. The medium is then coagulated in a slanting position at $90^{\circ} \mathrm{C}$ for 60 minutes. Reaction of the medium is about 6.1.

Despite the fact that only the egg yolk medium supports gross visible growth of the acid-fast organisms supposedly murine leprosy bacilli, the ability of the medium proved not so satisfactory. As previously described ${ }^{2)}$, all of the ingredients in the medium appeared to be necessary for growth of the organism. This paper aimed for the improvement of the medium.

The following modified egg yolk media were prepared by varying the concentration of the salts and the glycerol or by varying the $\mathrm{pH}$ of the medium. The test media in Experiments I and II had the same composition as the original (standard) one except that the amount of monopotassium phosphate in the salt solution was varied to give concentrations ranging from 0.3 to 3 per cent. As a result, these slants possessed different $\mathrm{pH}$ values from that of the standard (Table 1). In Experiment III, similarly, the test media had the same formula as the standard one except the concentration of sodium glutamate in the salt solution was altered from 1 to 0.5 or 2 per cent (Table 2). The glycerol was decreased or increased to give final concentrations ranging from 0.5 to 16 per cent in the case of the test media in Experiments IV and V (Table 3).

In Experiments VI-IX, the $\mathrm{pH}$ of the medium was adjusted to 6.4 to 7.0 either by adding dibasic sodium phosphate to the salt solution (Table 4) or by adding an aqueous sodium hydroxide solution to the medium before inspissation (Table 5).

A total of 169 subcultures of the supposed Hawaiian strain was used for these growth experiments. Small portions of the growth were transferred by a loop lightly on the middle of the surface of media and then the tubes were incubated at $37^{\circ} \mathrm{C}$ for 3 months. Observations were repeated weekly or biweekly to compare the size of the gross visible growth on the standard and modified egg yolk media with that of the negative control growth on Ogawa's egg medium inoculated in parallel.

Evaluation of the modified media was made according to whether the frequency of the positive growth on them is higher or not than that of the positive growth on the standard egg yolk medium. The results showed, however, that none of the modified egg yolk media tested were supperior to the original one. 


\section{鼠らい菌に関する研究}

（第 5 報） $1 \%$ 卵黄培地に混入されている $\mathrm{KH}_{2} \mathrm{PO}_{4}$, グルタミン酸

ナトリウム，グリセリンの量および培地の $\mathrm{pH}$ の検討

小川辰次平木美奈子

(浦和市立北宿病院, 北里研究所）（北里研究所）

（受付 1972年 2 月 15 日）

\section{緒言}

我々の使用している $1 \%$ 卵黄培地1)の中に混入されて いる種々の要素は, 鼠らい菌様抗酸菌の発育に不可欠の ものであることは，前に報告2したとおりである。しか し，その混入の量や培地の $\mathrm{pH}$ が適当であるかどうか は，まだ検討していない。これらの点を検討することに よって，1\%卵黄培地の性能を高めることができないか どうかと思い，実験したのでここに報告する。

\section{方 法}

\section{i 培地の作り方}

イ 標準培地 $\cdots \cdot \mathrm{KH}_{2} \mathrm{PO}_{4} 1.0 \mathrm{~g}$, グルタミン酸ナトリ ウ $41.0 \mathrm{~g}$, 溜水 $100 \mathrm{ml}$ の組成のものを基汁とする。基汁 $100 \mathrm{ml}$ ，グリセリン $6 \mathrm{ml}, 2 \%$ クカイト緑液 $6 \mathrm{ml}$, 卵 黄 $200 \mathrm{ml}$ をよくかきまぜて， $5 \mathrm{ml}$ 宛，中試験管に分注 し, 斜面として, $90^{\circ} \mathrm{C}, 1$ 時間, 凝固器でかためた。 $\mathrm{pH}$ は6.1〜6.2位である。

口 試作培地

a. $\mathrm{KH}_{2} \mathrm{PO}_{4} \cdots \mathrm{KH}_{2} \mathrm{PO}_{4}$ の基汁えの混入量を, 0.3 $\%, 0.5 \% ， 2 \% ， 3 \%$ と変更しただけで，その他の組 成は標準培地と全く同様である。このようにして作った 試作培地を(1), (2), (3), (4)とした。

b. グルタミン酸ナトリウム…a に準して，グルタ ミン酸ナトリウムの基汁への混入量を， $0.5 \% ， 2 \%$ と して作った試作培地を，(5)，(6)とした。

c. グリセリン…1\% 卵黄培地の全量に対して混入 するグリセリンの量を， $0.5 \% ， 1 \% ， 4 \% ， 8 \%, 16$ \%として作った試作培地を，(7)，(8)，(9)，(10)，(11)，とし た。

d. $\mathrm{Na}_{2} \mathrm{HPO}_{4} 12 \mathrm{H}_{2} \mathrm{O}$ の混入によって $\mathrm{pH}$ を修正した 培地 $\cdots .1 \%$ 卵黄培地の 基汁に0.5\%, $1 \%, 2 \%, 3$
\%に混入したもので作った試作培地を，それぞれ(12， (13), (144), (15) とし, 更に $\mathrm{Na}_{2} \mathrm{HPO}_{4} 12 \mathrm{H}_{2} \mathrm{O}$ と $\mathrm{KH}_{2} \mathrm{PO}_{4}$ を それぞれ $0.5 \%$ に混入した基汁で作った試作培地を(16) と した。

e. $\mathrm{NaOH}$ 液で $\mathrm{pH}$ を修正した培地…凝固する前 の $1 \%$ 卵黄培地, $100 \mathrm{ml}$ に対して $1 \% \mathrm{NaOH}$ 液, $2 \%$ $\mathrm{NaOH}$ 液， $3 \% \mathrm{NaOH}$ 液， $4 \% \mathrm{NaOH}$ 液を，それ ぞれ $2.0 \mathrm{ml}$ 宛加えてよくまぜて作った試作培地を， (17)， (18), (19), (20)とした。

これらの培地の $\mathrm{pH}$ の測定には，1本の培地に約 10 $\mathrm{ml}$ の溜水を加え，箸で培地をつぶして充分にまぜ，濾 紙で漉した濾液を日立の $\mathrm{pH}$ メーターで測定した。

ii 検討の仕方

$1 \%$ 卵黄培地を標準培地として, 被検の種々の試作培 地および $1 \%$ 小川培地を 2 本宛使用した。これらの培地 に菌株より集落の 1 片をとって, 斜面の中央におき, 綿 検を無孔のゴムのキャップにとりかえ， $37^{\circ} \mathrm{C} に 3$ カ月 培養し, $1 \sim 2$ 週に 1 回宛見て, 集落の大きくならない $1 \%$ 小川培地に比して, 集落の大きくなった時に陽性と した。なお 2 本使用の培地中の 1 本にだけ発淯した時も 陽性とし，雑菌の侵入したものは成績より除外した。そ して最後の判定の時に, 集落の縦と横の長さを, 試験管 の外よりはかり，大きさを比較した。使用した菌株は， 初代および種々の継代のハワイ株様抗酸菌, $37^{\circ} \mathrm{C}$, 約 $2 \sim 3$ 力月培養のもとであって, 継代にあたっては, な るべく同じ菌量になるよう心がけた。

\section{成 績}

a. $\mathrm{KH}_{2} \mathrm{PO}_{4}$ の混入量を種々にした試作培地

試作培地の $\mathrm{pH}$ は Table 1 に示したように, 標準培 地に比して, 混入量の少い時は, 高い $\mathrm{pH}$ を示し, 混 入量の多くなるにしたがって低い $\mathrm{pH}$ を示している。 
Table 1 Growth of the Acid-Fast Organisms, Supposedly M. lepraemurium, on the Egg Yolk Media Modified by Varying the Concentration of Monopotassium Phosphate

\begin{tabular}{|c|c|c|c|c|c|c|}
\hline \multirow{3}{*}{ Experiment } & \multirow{3}{*}{$\begin{array}{l}\text { No. of cultures } \\
\text { inoculated }\end{array}$} & \multicolumn{5}{|c|}{ No. of cultures giving positive growtha on } \\
\hline & & \multirow{2}{*}{$\begin{array}{l}1 \% \text { egg yolk } \\
\text { medium } \\
\text { (standard) }\end{array}$} & \multicolumn{4}{|c|}{ Modified egg yolk medium } \\
\hline & & & (1) & $(2)$ & (3) & (4) \\
\hline I & $\begin{array}{c}23 \\
(\mathbf{1 0 0} \%)\end{array}$ & $\left(\begin{array}{l}16 \\
70 \%)\end{array}\right.$ & $\begin{array}{c}9 \\
(39 \%)\end{array}$ & $\left(\begin{array}{l}10 \\
(44 \%)\end{array}\right.$ & $\cdots$ & . \\
\hline II & $\begin{array}{c}22 \\
(\mathbf{1 0 0} \%)\end{array}$ & $\begin{array}{l}21 \\
(\mathbf{9 5} \%)\end{array}$ & . & . & $\left(\begin{array}{l}20 \\
(91 \%)\end{array}\right.$ & $\begin{array}{l}19 \\
(86 \%)\end{array}$ \\
\hline \multicolumn{2}{|c|}{ i) Conc. of $\mathrm{KH}_{2} \mathrm{PO}_{4}$ in the salt solution } & ion $\ldots \ldots 1 \%$ & $0.3 \%$ & $0.5 \%$ & $2 \%$ & $3 \%$ \\
\hline \multicolumn{3}{|c|}{ 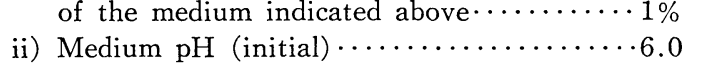 } & 6.4 & 6.3 & 5.6 & 5.7 \\
\hline
\end{tabular}

The sign $(\cdots)$ indicates no experiment.

Table 2 Growth of the Acid-Fast Organisms, Supposedly M. lepraemurium, on the Egg Yolk Media Modified by Varying the Concentration of Sodium Glutamate

\begin{tabular}{|c|c|c|c|c|}
\hline & \multirow{3}{*}{ Experiment } & \multicolumn{3}{|c|}{ No. of cultures giving positive growth on } \\
\hline & & \multirow{2}{*}{$\begin{array}{l}1 \% \text { egg yolk } \\
\text { meedium } \\
\text { (standard) }\end{array}$} & \multicolumn{2}{|c|}{ Medified egg yolk medium } \\
\hline & & & (5) & (6) \\
\hline & III & $\begin{array}{c}8 \\
(47 \%)\end{array}$ & $\begin{array}{c}8 \\
(47 \%)\end{array}$ & $\begin{array}{c}8 \\
(47 \%)\end{array}$ \\
\hline \multicolumn{2}{|c|}{$\begin{array}{l}\text { i) Conc. of sodium glutamate in the salt } \\
\text { solution of the medium indicated above }\end{array}$} & … $1 \%$ & $0.5 \%$ & $2 \%$ \\
\hline ii) 1 & Medium $\mathrm{pH}$ & $\cdots \cdots \quad 6.2$ & 6.1 & 6.1 \\
\hline
\end{tabular}

(1)，(2)試作培地の実験および(3)，(4)の試作培地の春験 は, ともに 3 回宛行われたが, 前者を実験 I, 後者を実 験II として綜括した。使用した菌株は，2 代が 5 株，3 代が16株, 4 代が 18 株, 5 代が 9 株, 合計 51 株であった が, 雑菌の侵入したものが 6 株あった。それで判定の対 象となったものは45株となる。

陽性率は Table 1 に示したようで, 試作培地の陽性 率は何れも低い。殊に $\mathrm{KH}_{2} \mathrm{PO}_{4}$ の少量混入の(1), (2)の 試作培地が, 多量混入の (3), (4)の試作培地に比して, ず っと低い。なお試作培地においては，標準培地に比し て, 集落の小さいものが多い。

b. グルタミン酸ナトリウムの混入量を種々にした試 作培地

試作培地の $\mathrm{pH}$ は標準培地と大差ない。使用した菌 株は，初代が 7 株， 2 代が 8 株，4 代が 1 株，10代が 2 株, 合計18株で，2回に亘って実験した。これを綜括し て実験IIIとした。1株に雑菌の侵入があったので, 判定 の対象となったのは17株である。陽性率は Table 2 に 示したとおりで，試作培地の(5)，(6)，と標準培地の間に
は差が無かった。また集落は, (5)では標準培地と大差が なかったが， (6)の試作培地では，小さいものが多かっ た。

c. グリセリンの混入量を種々にした試作培地

試作培地の $\mathrm{pH}$ は, 何れもほぼ同じで, 標準培地と 大差ない。用いた菌株は，初代が 5 株， 2 代が 5 株， 3 代が 1 株， 4 代が 6 株, 5 代が 3 株, 6 代が 11 株, 7 代 が 7 株, 合計 38 株である。この中 1 株が雑菌の侵入を認 めたので, 判定の対象となったものは37株である。(7), (8)の試作培地の実験は 2 回, (9), (10), (11)の試作培地の実 験は 3 回行った。これらを実験 $\mathrm{IV}$, 実験 Vとして 綜括 し, Table 3 に陽性率を示した。陽性率は, いずれの試 作培地においても，標準培地に比して低い。

殊に多量に混入した(10, (11)の試作培地では 1 株も発育 していない。集落の大きさは，(7)，(8)の試作培地ではい ずれも小さく, (9の試作培地では, 一部小さなものもあ ったが，大部分は標準培地と大差がなかった。

d. $\mathrm{Na}_{2} \mathrm{HPO}_{4} \cdot 12 \mathrm{H}_{2} \mathrm{O}$ の混入により，培地の $\mathrm{pH}$ を 種々に修正した試作培地。 
Table 3 Growth of the Acid-Fast Organisms, Supposedly M.lepraemurium, on the Egg Yolk Media Modified by Varying the Concentration of Glycerol

\begin{tabular}{|c|c|c|c|c|c|c|c|}
\hline \multirow{3}{*}{ Experiment } & \multirow{3}{*}{$\begin{array}{l}\text { No. of cultures } \\
\text { inoculated }\end{array}$} & \multicolumn{6}{|c|}{ No. of cultures giving positive growth on } \\
\hline & & \multirow{2}{*}{$\begin{array}{c}1 \% \text { egg yolk } \\
\text { medium } \\
\text { (standard) }\end{array}$} & \multicolumn{5}{|c|}{ Modified egg yolk medium } \\
\hline & & & $(7)$ & $(8)$ & (9) & $(10)$ & (11) \\
\hline IV & $\begin{array}{c}17 \\
(100 \%)\end{array}$ & $\left(\begin{array}{l}10 \\
\mathbf{5 9} \%)\end{array}\right.$ & $\begin{array}{c}3 \\
(18 \%)\end{array}$ & $\left(\begin{array}{l}6 \\
(35 \%)\end{array}\right.$ & $\cdots$ & . & $\cdots$ \\
\hline $\mathrm{V}$ & $\begin{array}{c}20 \\
(100 \%)\end{array}$ & $\begin{array}{l}12 \\
(60 \%)\end{array}$ & $\cdots$ & $\cdots$ & $\begin{array}{c}8 \\
(50 \%)\end{array}$ & $\left(-\frac{0}{-}\right)$ & $\left(\frac{0}{-}\right)$ \\
\hline \multicolumn{2}{|c|}{$\begin{array}{l}\text { i) Final conc. of glycerol in the } \\
\text { medium indicated above } \ldots . . . .\end{array}$} & $\cdots 2 \%$ & $0.5 \%$ & $1 \%$ & $4 \%$ & $8 \%$ & $16 \%$ \\
\hline \multicolumn{2}{|c|}{ ii) Medium $\mathrm{pH}$ (initial) $\ldots \ldots \ldots \ldots$} & $\cdots \cdots 6.1$ & 6.1 & 6.1 & 6.0 & 6.1 & 6.1 \\
\hline
\end{tabular}

The sign $(\cdot \cdot)$ indicates no experiment.

Table 4 Growth of the Acid-Fast Organisms, Supposedly M. lepraemurium, on the Egg Yolk Media Modified in $\mathrm{pH}$ by Adding Dibasic Sodium Phosphate

\begin{tabular}{|c|c|c|c|c|c|c|c|c|}
\hline \multirow{3}{*}{\multicolumn{2}{|c|}{ Experiment }} & \multirow{3}{*}{$\begin{array}{l}\text { No. of cultures } \\
\text { inoculated }\end{array}$} & \multicolumn{6}{|c|}{ No. of cultures giving positive growth on } \\
\hline & & & \multirow{2}{*}{$\begin{array}{c}1 \% \text { egg yolk } \\
\text { medium } \\
(\text { standard })\end{array}$} & \multicolumn{5}{|c|}{ Modified egg yolk medium } \\
\hline & & & & (12) & (13) & (14) & (15) & (16) \\
\hline & VI & $\begin{array}{c}14 \\
(100 \%)\end{array}$ & $\begin{array}{l}13 \\
(93 \%)\end{array}$ & $\cdots$ & $\begin{array}{c}6 \\
(43 \%)\end{array}$ & $\begin{array}{c}4 \\
(29 \%)\end{array}$ & $\left(\frac{0}{-}\right)$ & $\cdots$ \\
\hline & VII & $\begin{array}{c}15 \\
(100 \%)\end{array}$ & $\begin{array}{l}10 \\
(67 \%)\end{array}$ & $\begin{array}{c}9 \\
(60 \%)\end{array}$ & $\begin{array}{c}9 \\
(60 \%)\end{array}$ & . & $\cdots$ & $\cdots$ \\
\hline & VIII & $\begin{array}{c}25 \\
(100 \%)\end{array}$ & $\begin{array}{l}15 \\
(60 \%)\end{array}$ & . & . & . & . & $\left(\begin{array}{l}13 \\
(\mathbf{5 2} \%)\end{array}\right.$ \\
\hline \multicolumn{9}{|c|}{$\begin{array}{l}\text { i) Conc. in salt sol. of the medium } \\
\text { indicated above }(\%):\end{array}$} \\
\hline & (a. $\mathrm{KH}_{2} \mathrm{PO}$ & $\ldots \ldots \ldots \ldots \ldots \ldots$ & $\cdots \cdots 1$ & 1 & 1 & 1 & 1 & 0.5 \\
\hline & $\left\{\begin{array}{l}\text { b. } \mathrm{Na}_{2} \mathrm{HPC} \\
\text { f }\end{array}\right.$ & ${ }_{4} \cdot 12 \mathrm{H}_{2} \mathrm{O} \cdots \ldots$ & $\cdots \cdots 0$ & 0.5 & 1 & 2 & 3 & 0.5 \\
\hline ii) & Medium pI & (initial) $\ldots \ldots$ & $\cdots \cdots 6.2$ & 6.4 & 6.6 & 6.8 & 6.9 & 6.4 \\
\hline
\end{tabular}

The sign $(\cdot$.$) indicated no experiment.$

Table 5 Growth of the Acid-Fast Organisms, Supposedly M. lepraemurium, on the Egg Yolk Media Modified in $\mathrm{pH}$ by Adding Sodium Hydroxide

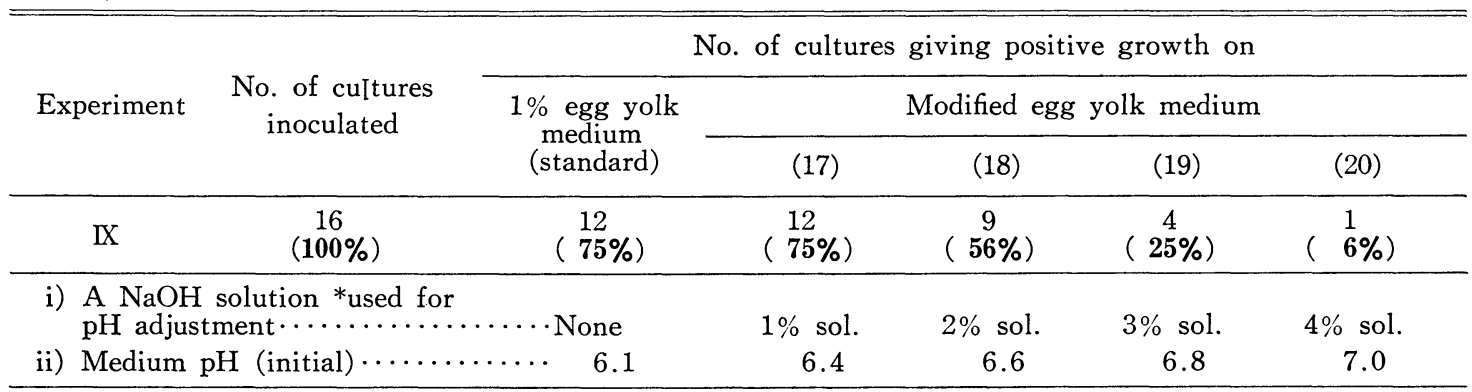

*) Two $\mathrm{ml}$. was added to each $100 \mathrm{ml}$. of the $1 \%$ egg yolk medium before inspissation. 
試作培地の $\mathrm{pH}$ は，Table 4 に見るように6.4 6.9 を示している。用いた菌株は，初代が11株， 2 代が 5 株， 3 代が 10 株， 4 代が 10 株， 5 代が 11 株， 6 代が 1 株， 7 代が 2 株， 9 代が 5 株， 10 代が 3 株，合計 58 株で ある。4 株に雑菌の侵入があったので 54 株が判定の対象 となった。(19)，(13)の試作培地の実娩が 2 回，(13)，(14)，(15) の試作培地の実験が 2 回, (16)の試作培地の実験を 3 回行 った。これをVI，VII，VIIIの実験としてまとめた。陽性率 は Table 4で見るように，いづれの試作培地において も，標準培地にくらべると低い。そして(15)試作培地で は，1株も発育していない。試作培地(13の陽性率が，実 験VI と実験VII とで著明の差があることに眼がつく。次に 集落の大きさは，試作培地においては概して小さいもの が多かった。

e. $\mathrm{NaOH}$ 液の混入により，培地の $\mathrm{pH}$ を種々に修 正した試作培地,

試作培地の $\mathrm{pH}$ は Table 5 でみるように, 6.4 7.0 であった。使用した菌株は，初代が 2 株， 3 代が 4 株, 5 代が 2 株， 6 代が 3 株， 8 代が 4 株，9代が 3 株，合 計18株であるが，2株に雑菌の侵入を見たので，判定の 対象となったものは16株である。陽性率は Table 5 で 見るように，(17)の試作培地のみが標準培地と同率を示し たが，その他の試作培地では，いずれも低く, $\mathrm{pH} 7.0$ に近づくに従って，陽性率は次第に低下した。集落の大 きさは，標準培地に比して小さいものが多かった。

\section{考察}

我々の使用している $1 \%$ 卵黄培地は，八ワイ株样抗酸 菌，の集落の発育を示すとは云え，満足すべき性能のも のではない。それで今回は， $\mathrm{KH}_{2} \mathrm{PO}_{4}$, グルタミン酸ナ トリウム，グリセリンの混入量が果して適当であるかど うか，培地の $\mathrm{pH}$ の6.1 6.2が，はたして適当である かどうかを検討するために，種々の量に混入した試作培 地，および種々の $\mathrm{pH}$ の試作培地を作って実験した。そ の結果は前述のように，予期に反して，1\%卵黄培地よ りもすぐれたものはなかった。即ち $1 \%$ 卵黄培地の種々 の要素の混入量は, 現在までのところ, 本来のままの量 が最もよいし， $\mathrm{pH}$ も本来の6.1 6.2 程度が最もよいこ とがわかった。しかしこの事実は, 1 \%卵黄培地の性能を 高める方法を，まだつかんでないと云うことであって， さらにこの培地の改良の余地を多分に残しているむのと 思われる。なお $\mathrm{Na}_{2} \mathrm{HPO}_{4} \cdot 12 \mathrm{H}_{2} \mathrm{O}$ の混入の(18陚作培 地が，第VI実験と第VI実験で陽性率に差を示したのは， 集落の 1 片を培地斜面にそっとのせるといった様な培養
の手技のための誤差によるのではなかろうかと推定して いる。今回の実験によって, 1 \%卵黄培地の $\mathrm{KH}_{2} \mathrm{PO}_{4}$, グルタミン酸ナトリウム,グリセリンの最も適当の量が, $1 \%$ 小川培地に混入されている量と全く同じであること がわかった。また $\mathrm{Na}_{2} \mathrm{HPO}_{4} 12 \mathrm{H}_{2} \mathrm{O}$ を培地に加えるこ とによって，発育が悪くなることも $1 \%$ 小川培地と全く 同様であった。これらのことは，我々の分離した鼠らい 菌様抗酸菌と人型結核菌とが，似ている性状の一面を示 しているものと思われるが，しかし我々の分離した鼠ら 、菌様抗酸菌は $\mathrm{pH} 6.1$ 前後の $1 \%$ 卵黄培地にのみ発育 し，人型結核菌の最む良く発育を示す $\mathrm{pH}$ 6.6前後の全 卵の $1 \%$ 小川培地に発育しないことは，鼠らい菌様抗酸 菌と人型結核菌とは，全く異なった性状の一面を示して いるものと思われる。

\section{綜 括}

$1 \%$ 卵黄培地を標準培地とし，培地中に混入されてい る $\mathrm{KH}_{2} \mathrm{PO}_{4}$ ，グルタミン酸ナトリウム，グリセリンを種 々の量に混入した種々の試作培地および $\mathrm{Na}_{2} \mathrm{HPO}_{4} \cdot 12$ $\mathrm{H}_{2} \mathrm{O}, \mathrm{NaOH}$ 液を加えて作った種々の $\mathrm{pH}$ の試作培地 に，初代あるいは種々の継代の八ワイ株様抗酸菌の集落 の一片を, 培地斜面に静かにおき， $37^{\circ} \mathrm{C} 3$ カ月間培養 し, 陽性率, 発育した集落の大きさを判定の基準として 比較した結果，標準培地よりすぐれた性能の培地は見ら れなかった。

（本論文の要旨は昭和46年10月の第20回日本瀨学会東 部地方会に扔いて発表した。本研究に終始御指導と御鞭 撻を頂いた故内田三千太郎博士に感謝する。）

\section{文献}

1）小川辰次, 本村恵子：鼠らい菌化関する研究, （第 1 報）鼠らい菌培養の試み，レプラ， 38 : 247, 1969.

Tatsuji Ogawa and Keiko Motomura: Studies on Murine Leprosy Bacillus., Attempt to cultivate in vitro the Hawaiian strain of mycobacterium lapraemurium. Kitasato Arch. of Exp. Med., 43:21, 1970.

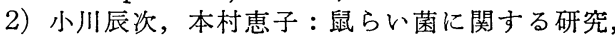
（第 2 報）我々の分離した 菌の性状に関するそ の後の成績と, $1 \%$ 卵黄培地の吟味, レプラ, $40: 9,1971$.

Tatsuji Ogawa and Keiko Motomura: Studies on Murine Leprory Bacillus. 2. Further characteristics of slow growing acid-fast organismus isolatd from experimental mice with Hawaiian strain and investigation of the $1 \%$ egg yolk medium. Kitasato Arch of Exp. Med. 44 : 37, 1971. 